\title{
Insulin-Glucagon Substrate Interrelations in the Fetal Sheep
}

\author{
ROBERT H. FISER, JR., (31) ALLEN ERENBERG, MARK A. SPERLING, \\ WILLIAM OH, AND DELBERT A. FISHER \\ Department of Pediatrics, UCLA-Harbor General Hospital, Torrance, California, USA
}

\section{Extract}

Twenty-four studies were conducted in 14 sheep fetuses to investigate the pancreatic islet $\alpha$ and $\beta$ cell responses to substrate infusions. The studies were conducted between 100 days gestation and near term, using indwelling vascular catheters for infusions and blood sampling. Constant glucose infusions $(6 \mathrm{mg} / \mathrm{kg} / \mathrm{min})$ produced a significant rise in the mean concentration of insulin in plasma by $105 \mathrm{~min}$, but no change in glucagon in plasma was observed. Near term $(>135$ days) the mean plasma insulin increment with constant glucose infusion was significantly greater and occurred sooner than in fetuses early in gestation ( $<110$ days), but again no plasma glucagon response was observed. The mean steady state glucose concentration in response to the $6 \mathrm{mg} / \mathrm{kg} / \mathrm{min}$ glucose infusion was similar early and late in gestation, even though the steady state plasma level of insulin in plasma was higher in the late gestation fetuses. Alanine infused into the fetus did not alter concentrations of glucose, insulin, or glucagon in plasma. These data suggest that changes in plasma concentrations of insulin and glucagon are not important in the regulation of substrate metabolism during fetal life. Moreover, the pancreatic islet $\beta$ cell secretion response seems to mature earlier than the $\alpha$ cell response.

\section{Speculation}

The failure of glucagon to respond to alanine stimulation during fetal life suggests immaturity of glucagon control of gluconeogenesis from amino acids. The low levels of activity of key glucagon-dependent gluconeogenic enzymes reported in liver of the newborn rat $(7,8)$ supports this view. These observations suggest the possibility that gluconeogenesis from amino acids may not represent a major metabolic pathway in the sheep fetus.

For many years glucose has been considered to be the principal metabolic fuel of the developing fetus. Recently, however, it has been suggested that glucose accounts for only about $50 \%$ of the caloric needs of the fetal sheep (13), the remaining energy requirement being met by amino acids, short chain fatty acids, or as yet unidentified substrates (10). The hormonal signals for control of substrate flow along intermediary metabolic pathways in the fetus are not well delineated. Results of studies of fetal plasma insulin responses to a glucose load in several species are conflicting; insulin levels have been described as either increasing in sheep $(4,5,9)$ and man $(17$, 21 ) or remaining unchanged in man (2), monkeys (18), and sheep (25) in response to stimulation. Thus the present studies were conducted to characterize fetal pancreatic islet $\alpha$ and $\beta$ cell responses to substrate infusions utilizing the chronically catheterized fetal sheep preparation both early and late in gestation.

\section{METHODS AND MATERIALS}

Fourteen healthy date-bred pregnant ewes with gestational ages ranging from 100-145 days were studied. The chronic indwelling catheter preparation was utilized and has been described previously (14). Briefly, a laparotomy through a left flank incision was performed using spinal anesthesia and aseptic technique. Either a jugular vein and carotid artery or a femoral vein and artery were isolated and catheterized, depending on whether the fetal head or hind limb was most conveniently exposed. Following catheter placement, the fetus was returned to the uterine cavity and the laparotomy closed. The catheters were exteriorized, marked, and secured on the mother's back. The ewes usually began to ambulate with 6-8 hr after surgery. Antibiotics (Ampicillin, $2 \mathrm{~g}$ intramuscularly, and Kanamycin, $0.5 \mathrm{~g}$ intramuscularly) were administered daily for 5 days. Studies were performed 3-6 days postsurgery, at which time maternal dietary intake had returned to normal and fetal blood gases and $\mathrm{pH}$ had stabilized within normal limits.

One group of eight animals received $2-\mathrm{hr}$ constant infusions of glucose $(6 \mathrm{mg} / \mathrm{kg} / \mathrm{min})$ by means of a Holter constant infusion pump. In another group of six animals, a similar glucose infusion protocol was used, but at the end of $90 \mathrm{~min}$ the infusion rate was doubled to $12 \mathrm{mg} / \mathrm{kg} / \mathrm{min}$ and continued for another $90 \mathrm{~min}$. In two animals a continuous infusion of saline was given at similar rates over the same time period. Blood was drawn at.15-min intervals throughout the infusion periods for blood glucose measurement and at specified time intervals $(0,45,75,105,135,165$, and $180 \mathrm{~min}) ; 2.5-\mathrm{ml}$ blood samples were collected in syringes rinsed in $10 \%$ EDTA These samples were placed promptly into chilled tubes containing EDTA plus $0.1 \mathrm{ml}$ Trasylol (28), immediately spun in a cold centrifuge at $2,000 \mathrm{rpm}$, and the plasma separated and stored at $-4^{\circ}$ until assayed for insulin and glucagon.

Alanine was infused into a third group of 10 fetuses and 2 adult sheep in a dose of $1 \mathrm{mM} / \mathrm{kg}$ of estimated body weight. The alanine solution (29) was diluted with sterile saline; half was given as an initial bolus injection and the remaining half was infused over a 10-min period. Two-milliliter blood samples were collected at $-30,-15,0,5,10,15,30,45$, and $60 \mathrm{~min}$. These were processed as described and analyzed for insulin, glucagon, and glucose.

In all studies blood glucose was measured by a glucose oxidase method (16). Immunoreactive insulin was measured by a modification of the double antibody technique of Morgan and Lazarow (19). Glucagon was assayed using a double antibody radioimmunoassay developed in our laboratory (23); this radioimmunoassay is sensitive to $20 \mathrm{pg}$ glucagon/tube $(200 \mathrm{pg} / \mathrm{ml})$ and cross-reacts approximately $20 \%$ (1/5) with gut glucagon or glucagon-like material. Blood levels of glucagon below $200 \mathrm{pg} / \mathrm{ml}$ are arbitrarily recorded as 200 $\mathrm{pg} / \mathrm{ml}$. 
To determine substrate infusion rates, fetal body weight was estimated from a nomogram of fetal body weight versus gestational age (22); absolute fetal weight was determined for each fetus at the time of caesarean section. The Student paired $t$ test was used to compare mean results of control and experimental samples.

\section{RESULTS}

Table 1 summarizes gestational age, fetal weight, and infusion rate of glucose for each fetus studied. All fetuses were normal weight for age and ranged in gestational age from 100-145 days at the time of the initial study.

Glucose, insulin, and glucagon responses to the constant infusion of glucose are depicted in Figure 1. Steady state glucose concentrations were reached within $45 \mathrm{~min}$ and persisted throughout the study period at values $6-8 \mathrm{mg} / 100$ $\mathrm{ml}$ above control levels during the $6 \mathrm{mg} / \mathrm{kg} / \mathrm{min}$ glucose infusion. Prior studies have shown that this infusion rate was necessary to raise fetal glucose concentrations consistently. Maternal blood glucose concentrations were $20-25 \mathrm{mg} / 100 \mathrm{ml}$ greater than the respective fetal values so that the maternal to fetal gradient was maintained, and the infusions produced no changes in maternal glucose or insulin concentrations.

Figure 1 indicates that fetal insulin levels tended to increase above control values within $45 \mathrm{~min}$ after the beginning of the glucose infusion. However, the increment was not significant until $105 \mathrm{~min}$ after the infusion was begun. At this time the mean concentration was increased approximately twofold above the control level of 20 microunits $/ \mathrm{ml}$. The mean plasma glucagon concentration during the control period was approximately $320 \mathrm{pg} / \mathrm{ml}$ and tended to decrease slightly after glucose administration. However, this decrease was not statistically significant at any time, perhaps because of the lower level of sensitivity of $200 \mathrm{pg} / \mathrm{ml}$ in the glucagon assay.

During the course of these studies it seemed that the increment in plasma insulin in response to glucose was greater in the fetuses studied late in gestation. To assess this possibility, insulin responses were analyzed in two groups according to gestational age. Early gestation fetuses were defined as less than 110 days of gestation and late gestation fetuses as greater than 135 days. The results are shown in Figure 2; the mean response of insulin in plasma to the 6 $\mathrm{mg} / \mathrm{kg} / \mathrm{min}$ glucose infusion rate was greater in fetuses late in gestation and the difference was seen within $45 \mathrm{~min}$ after

Table 1. Glucose infusion rates, gestational age, and weight of fetal sheep

\begin{tabular}{|c|c|c|c|c|}
\hline \multirow[b]{2}{*}{ Sheep no. } & \multirow[b]{2}{*}{$\begin{array}{c}\text { Gestational age at } \\
\text { initial time of study, days }\end{array}$} & \multirow[b]{2}{*}{$\begin{array}{l}\text { Fetal weight, } \\
\mathrm{kg}\end{array}$} & \multicolumn{2}{|c|}{$\begin{array}{l}\text { Infusion rate } \\
\mathrm{mg} / \mathrm{kg} / \mathrm{min}\end{array}$} \\
\hline & & & $1 \mathrm{st}$ & 2nd \\
\hline$C-29$ & 100 & 1.1 & 8.0 & 20.0 \\
\hline$C-30$ & 100 & 1.8 & 6.0 & \\
\hline$C-24$ & 109 & 1.6 & 6.2 & \\
\hline$C-15$ & 110 & 2.0 & 6.4 & \\
\hline$C-20$ & 134 & 4.4 & 6.0 & 12.8 \\
\hline$C-19$ & 135 & 3.8 & 5.9 & \\
\hline$C-23$ & 135 & 3.3 & 5.4 & 11.8 \\
\hline$C-12$ & 140 & 3.1 & 6.0 & \\
\hline$C-22$ & 140 & 4.2 & 6.2 & 12.2 \\
\hline$C-26$ & 141 & 4.7 & 2.8 & 5.5 \\
\hline$C-14$ & 143 & 3.0 & 6.0 & \\
\hline$C-25$ & 143 & 4.8 & 5.4 & 10.4 \\
\hline$C-16$ & 145 & 3.5 & 6.9 & \\
\hline$C-17$ & 145 & 3.5 & 5.7 & \\
\hline
\end{tabular}

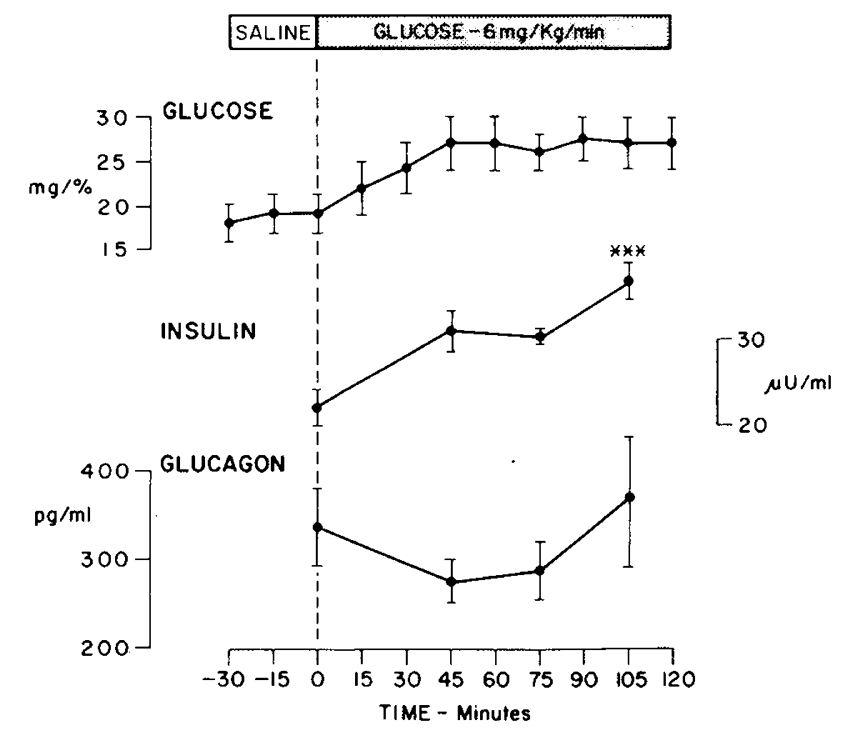

Fig. 1. Sequential response of plasma glucose (milligrams per $100 \mathrm{ml}$ ) insulin (microunits per milliliter), and glucagon (picograms per milliliter) concentrations during constant infusions of glucose after saline infusions in combined early and late gestational fetal sheep. Each plotted point and deviation represents the mean and standard error of eight sheep. Gestational ages ranged from 100-145 days. The asterisks indicate the difference between the mean concentration of insulin at 105 min compared with that at zero time by paired $t$ test. $* * *: p<$ 0.001 .
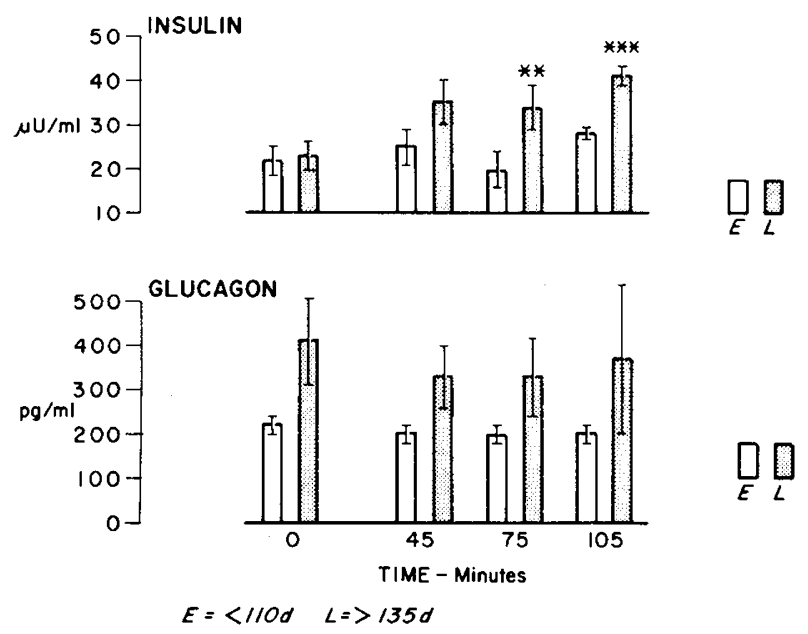

Fig. 2. Plasma insulin (microunits per milliliter) and glucagon (picograms per milliliter) levels during constant glucose infusions in fetal sheep early and late in gestation. The zero time concentrations represent base-line insulin and glucagon levels. The open bars represent animals 110 days or less in gestation, the stippled bars animals over 135 days gestation. Each bar and line represents the mean and SEM of four animals. The base-line or zero time concentrations of insulin and glucagon are similar in both early and late gestation fetuses. The asterisks indicate that the difference between the mean insulin concentration in early and late fetuses is significant. ${ }^{* *}: p<0.01 ; * * *$ : $p<0.01$. There was no increase in concentrations of glucagon in plasma over base-line in either group of fetuses.

beginning the infusion. The difference was significant at both the 75- and 105-min time periods. The mean blood glucagon concentration remained unchanged during glucose infusions both early and late in gestation, although the base-line level was slightly higher late in gestation. Base-line glucose and insulin levels were not significantly different in early and late gestation. However, the small number of animals may have obscured any significant differences in the base-line glucagon 
levels in the early and late gestational fetuses.

The responses of blood glucose, insulin, and glucagon to stepwise elevations of blood glucose are depicted in Figure 3. These studies were done in the five older gestation fetuses and one young fetus. Steady state glucose concentrations were reached within $45 \mathrm{~min}$ as in the earlier studies. After $90 \mathrm{~min}$ a new steady state level occurred in response to the higher glucose infusion rate. However, this second steady state glucose level was somewhat more variable than that at the lower infusion rate: The mean plasma insulin concentration was increased significantly by $45 \mathrm{~min}$. A further increase over the 45 -min level was present at $165 \mathrm{~min}$, but at the $180-\mathrm{min}$ time period the level had fallen slightly. Glucagon levels tended to be depressed during the glucose infusions, particularly at the higher infusion rate, but because of large standard errors and the lower level of sensitivity of the assay, the changes were not significant.

The changes in blood insulin, glucagon, and glucose in response to the fetal alanine infusions are shown in Figure 4. In these studies, done both early $(n=4)$ and late $(n=6)$ in gestation, no significant changes were observed in any of the measured variables. In the two adult sheep, glucose levels

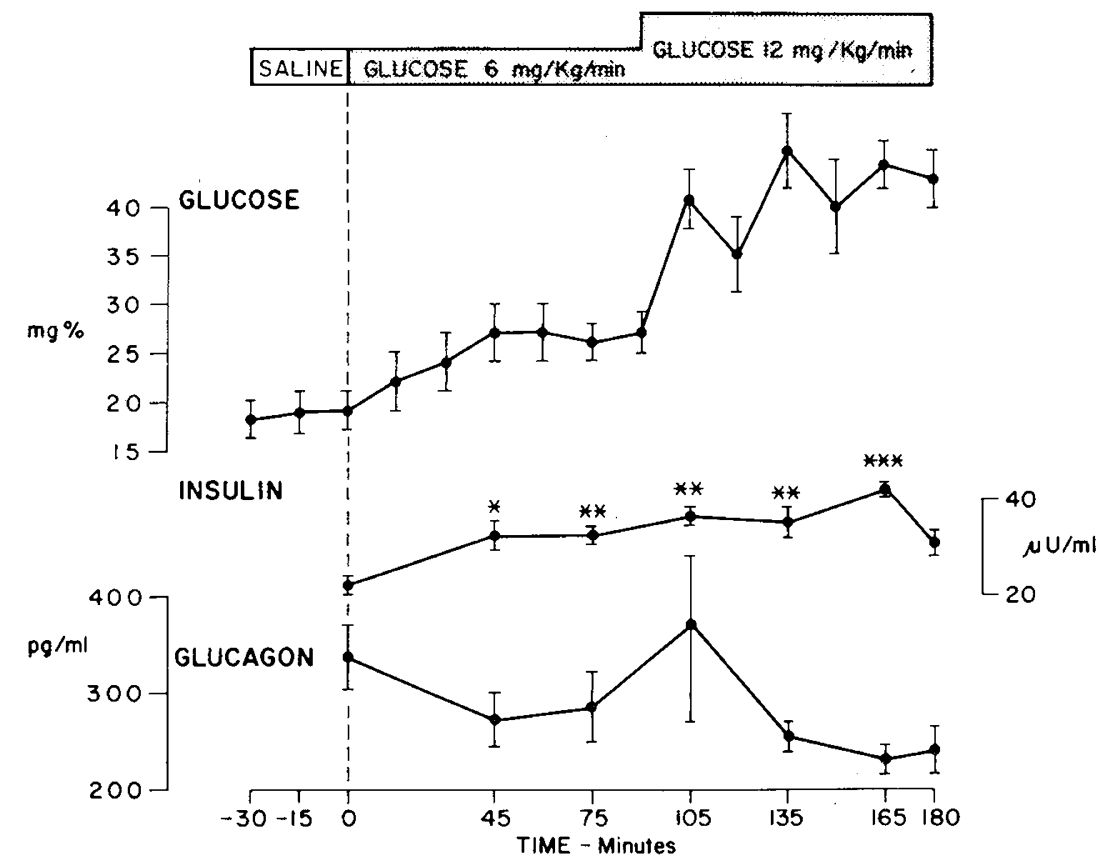

Fig. 3. Sequential responses of glucose in plasma (milligrams per $100 \mathrm{ml}$ ), insulin (microunits per milliliter), and glucagon (picograms per milliliter) concentrations during constant infusion of saline or glucose. Glucose was infused at two rates: 6 and $12 \mathrm{mg} / \mathrm{kg} / \mathrm{min}$. Each plotted point and line represent the mean and SE of six sheep. One fetus was 100 days gestation; the remainder were $134-145$ days' gestation. The asterisks indicate the difference between the mean insulin concentrations at each time period versus base-line values. The value at 165 min was also increased $(P<0.01)$ over the 45 -min period. ${ }^{*} P<0.05 ;{ }^{*}: P<0.01 ; * * *: P<0.001$.

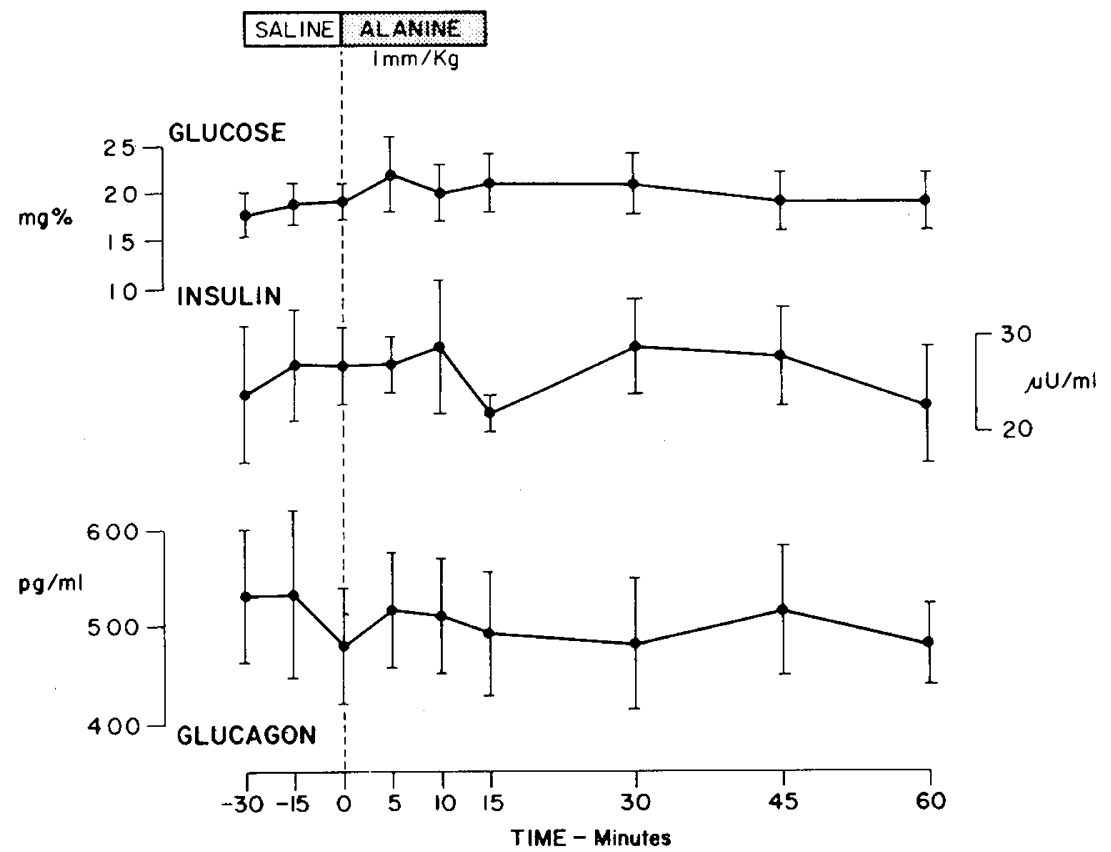

Fig. 4. Sequential response of glucose in plasma (milligrams per $100 \mathrm{ml}$ ), insulin (microunits per milliliter), and glucagon (picograms per milliliter) concentrations during and after saline or alanine infusions. Each plotted point and line represents the mean and SEM of 10 fetal sheep. 
increased $8-10 \mathrm{mg} / 100 \mathrm{ml}$ at $30 \mathrm{~min}$ and glucagon levels increased from base-line values of 212 and $103 \mathrm{pg} / \mathrm{ml}$ to levels of 712 and $395 \mathrm{pg} / \mathrm{ml}$, respectively, at $30 \mathrm{~min}$.

\section{DISCUSSION}

The chronic infusion of glucose provides a more sustained physiologic stimulus for studying fetal insulin and glucagon secretion than does an acute glucose injection. Acute glucose injections are difficult to interpret for several reasons: (1) the increased blood glucose concentrations in the fetus reverse the normal maternal-fetal blood glucose gradient so that the possibility of significant fetal to maternal placental transfer of glucose exists at the early high fetal blood glucose levels; (2) the increase in blood glucose is not prolonged enough or sustained enough to establish steady state conditions for insulin secretion. These factors may help to explain some of the earlier conflicting data regarding insulin secretion responses in several species. Reported insulin responses to glucose injections in both the monkey (18), rat (15), and man (21) were minimal, whereas, in the fetal sheep, a response to acute glucose or fructose injection has been observed by some authors $(4,5,9)$ and not by others $(25)$. The present results suggest that some of this variation may relate to the degree and duration of the stimulus.

As noted in Figure 1, fetal serum insulin levels were not significantly increased until $105 \mathrm{~min}$ after beginning the chronic infusion. However, we did not measure serum concentrations before $45 \mathrm{~min}$. Studies of fetal rat pancreatic insulin release conducted in vitro also have shown a delayed and obtunded response to glucose, and this response can be markedly enhanced by the addition of caffeine or theophylline to the incubation media (15). Similar enhancement of insulin release by theophylline has been reported in the monkey fetus by Chez et al. (11). These investigators found that glucose combined with theophylline elicited a prompt rise in plasma insulin in the primate fetus, whereas glucose or theophylline alone did not. Insulin levels were also promptly increased by the infusion of the dibutyryl derivative of cyclic $3^{\prime}, 5^{\prime}$. adenosine monophosphate to the fetus. These observations suggest that the limitation in fetal insulin release in response to glucose may relate to immaturity of the $\beta$ cell cyclic AMP system.

However, it is clear from the present studies that the pancreatic islet $\beta$ cell in the fetal sheep is capable of responding with release of immunoreactive insulin after relatively modest increments in mean blood sugar concentration if the increment is sustained. These studies also indicate that the fetal insulin response to a glucose stimulus increases in the sheep with increasing gestational age, although baseline insulin concentrations were similar. Thus, in the fetal sheep, as in the human fetus (2), the insulin secretory response to glucose is delayed and obtunded but appears to improve with increasing gestational age.

Under the steady state conditions of the present studies, the glucose disposal rate represents the sum of the glucose infusion rate and any continuing maternal to fetal placental glucose transfer. Since the latter was not quantified, it is not possible to estimate precisely disposal from the rate of infusion. However, the steady state plasma glucose concentration in response to the $6 \mathrm{mg} / \mathrm{kg} / \mathrm{min}$ glucose infusion rate was similar both early and late in gestation, which suggests either that glucose disposal in the fetus is not insulin dependent or that the effect of insulin on glucose disposal decreased with age. The latter possibility seems less likely.

Glucagon has been identified in the fetal pancreas early in gestation (6). Moreover, in man and sheep, the placenta is impermeable to glucagon $(1,24)$, as to most other peptide hormones, so that fetal blood glucagon must be derived from the fetal pancreas. Earlier data in humans also suggest that glucagon levels in fetal blood are low and respond minimally to arginine infusion (6). The present results in the sheep fetus support this suggestion and indicate that pancreatic glucagon also is unresponsive to alanine in this species. In contrast, Wise et al. (27) described increased glucagon concentrations in cord blood of newborn infants after administration of alanine to women in labor. In addition, we have reported recently that alanine administration to newborn infants during the first 24 $\mathrm{hr}$ of life evokes modest increases in blood glucagon (23).

The blood glucagon levels in the present study probably reflect some gut glucagon or glucagon-like activity as well as pancreatic glucagon, since the antibody used for the radioimmunoassay shows some cross-reaction with gut glucagon standards. However, this in no way invalidates the results, since there is little or no gastrointestinal stimulation during intravenous glucose and alanine infusions. Moreover, the base-line glucagon levels in the fetal sheep in the present study are similar to those reported by Alexander et al. (3).

Felig and collaborators (12) have postulated the existence in adult man of a glucose-alanine cycle. Alanine has been shown to be a potent stimulus for glucagon secretion in both the dog (20) and man (26). Moreover, we have confirmed that alanine will evoke glucagon secretion in the adult sheep and in the human neonate (23). The results of the present studies indicate that alanine is not an inportant stimulus for glucagon secretion in the sheep fetus; the glucagon response to alanine infusion was minimal or absent (Fig. 4).

\section{SUMMARY}

Studies of insulin and glucagon concentrations in plasma have been conducted in fetal sheep in utero via indwelling vascular catheters. Chronic glucose infusions and acute alanine infusions were used as stimuli. The pancreatic insulin secretory response to glucose was relatively obtunded but some maturation of this response was observed with advancing gestational age. The pancreatic glucagon response was minimal in all fetuses studied. The pancreatic islet $\beta$ cell (insulin) secretion mechanism or mechanisms appear to mature earlier than the $\alpha$ cell (glucagon) secretion mechanism.

\section{REFERENCES AND NOTES}

1. Adam, P. A. J., King, K. C., Schwartz, R., and Teramo, K.: Human placental barrier to 125 I-glucagon early in gestation. J. Clin. Endocrinol. Metab., 34: 772 (1972).

2. Adam, P. A. J., Teramo, K., Raiha, N., Gitlin, D., and Schwartz, R.: Human fetal insulin metabolism early in gestation response to acute elevation of the fetal glucose concentration and placental transfer of human insulin I-131. Diabetes, 18: 409 (1969).

3. Alexander, D. P., Assan, R., Britton, H. G., and Nixon, D. A.: Glucagon in the foetal sheep. J. Endocrinol., 51: 597 (1971).

4. Alexander, D. P., Britton, H. G., Cohen, N. M., and Nixon, D. A. Plasma concentrations of insulin, glucose, free fatty acids and ketone bodies in the foetal and newborn sheep and the response to a glucose load before and after birth. Biol. Neonate, 14: 178 (1969).

5. Alexander, D. P., Britton, H. G., Mashiter, K., Nixon, D. A., and Smith, F. G., Jr.: The response of the foetal sheep in utero to intravenous glucose. Biol. Neonate, 15: 361 (1970).

6. Assan, R., and Boillot, J.: Pancreatic glucagon and glucagon-like material in tissue and plasma from human foetuses 6-26 weeks old. In: J. H. P. Jonxis, H. K. A. Visser, and J. A. Troelstra: Metabolic Processes in the Foetus and Newborn Infant, pp. 210-219 (The Williams and Wilkins Co., Baltimore, 1971).

7. Ballard, F. J.: The development of gluconeogenesis in rat liver; controlling factors in the newborn. Biochem. J., 124: 265 (1971).

8. Ballard, F. J., and Hanson, R. W.: Phosphoenolpyruvate carboxykinase and pyruvate carboxylase in developing rat liver. Biochem. J., 104: 866 (1967).

9. Basset, J. M., and Thorburn, G. D.: The regulation of insulin secretion by the ovine foetus in utero. J. Endocrinol., 50:59 (1971).

10. Cahill, G. F.: Prenatal nutrition of lambs, bears and babies? Pediatrics, 50: 357 (1972).

11. Chez, R. A., Mintz, D. H., and Hutchinson, D. L.: Effect of theophylline on glucagon and glucose-mediated plasma insulin 
responses in subhuman primate fetus and neonate. Metabolism, 20: 805 (1971).

12. Felig, P.: The glucose alanine cycle. Metabolism, 22: 179 (1973)

13. Gresham, E. L., James, E. J., Raye, J. R., Battaglia, F. C. Makowski, E. L., and Meshia, G.: Production and excretion of urea by the fetal lamb. Pediatrics, 50: 372 (1972).

14. Hobel, C. J., Emmanouilides, G. C., Townsend, D. E., and Yashiro, K.: Ligation of one umbilical artery in the fetal lamb. Obstet. Gynecol., 36: 582, (1970).

15. Lambert, A. E., Junod, A., Stauffacher, W., Jeanrenaud, B., and Renold, A. D.: Organ culture of fetal rat pancreas. I. Insulin release induced by caffeine and by sugars and some derivatives. Biochim. Biophys. Acta, 184: 529 (1969).

16. Marks, V.: An improved glucose oxidase method for determining blood, CSF, and urine glucose levels. Clin. Chim. Acta, 4: 395 , (1959).

17. Milner, R. D. G., and Hales, C. N.: Effect of intravenous glucose on concentration of insulin in maternal and umbilical cord plasma. Brit. Med. J., 1: 284, (1965).

18. Mintz, D. H., Chez, R. A., and Horger, E. O.: Fetal insulin and growth hormone metabolism in the subhuman primate. J. Clin. Invest., 48: 176 (1969).

19. Morgan, C. R., and Lazarow, A.: Immunoassay of insulin: Two antibody system. Diabetes, 12: 115 (1963).

20. Muller, W. A., Faloona, G. R., and Unger, R. H.: The effect of alanine on glucagon secretion. J. Clin. Invest. 50: 2215 (1971)

21. Obenshain, S. S., Adam, P. A. J., King, K. C., Teramo, K., Rairio, K. O., Raiha, N., and Schwartz, R.: Human fetal insulin response to sustained maternal hyperglycemia. New Engl. J. Med., 283: 566 (1970).

Copyright (c) 1974 International Pediatric Research Foundation, Inc.
22. Oh, W., Omori, K., Emmanoulides, G. C., and Erenberg, A.: Somatic growth, umbilical blood flow and substrate transfer in fetal sheep (submitted for publication).

23. Sperling, M. A., Delamater, P. V., Phelps, D., Fisher, R. H., Oh, W., and Fisher, D. A.: Spontaneous and amino acid stimulated glucagon secretion in the immediate postnatal period: Relation to glucose and insulin. J. Clin. Invest., 53: 1159 (1974).

24. Sperling, M. A., Erenberg, A., Fisher R. H., Jr., Oh, W., and Fisher, D. A.: Placental transfer of glucagon in sheep. Endocrinology, 93: 1435 (1973).

25. Willes, R. F., Boda, J. M., and Manns, J. G.: Insulin secretion by the ovine fetus in utero. Endocrinology, 84: 520 (1969).

26. Wise, I. K , Hendler, R and Felig, P. Evaluation of alpha-cell function by infusion of alanine in normal, diabetic and obese subjects. New Engl. J. Med., 288: 487 (1973).

27. Wise, J. K., Santokh, S. L., Hendler, R., and Felig, P.: Evidence of stimulation of glucagon secretion by alanine in the human fetus at term. J. Clin. Endocrinol. Metab., 37: 345 (1973).

28. FBA Pharmaceutical, New York; $0.1 \mathrm{ml}=1,000$ kallikrein units.

29. Sigma Chemical Company, St. Louis, Mo.

30. This research was supported in part by United States Public Health Service Grants nos. HD-04610, HD-04270, AM-05638, and HD-07087 from the National Institutes of Health, Bethesda, Maryland, and Harbor General Hospital-Attending Staff Association General Research Support G-1465 and RR-0425.

31. Requests for reprints should be addressed to: Robert $\mathrm{H}$. Fiser, Jr. M.D., University of Arkansas, 4301 W. Markham St., Little Rock Ark. 72204 (USA).

32. Accepted for publication July 18, 1974.

Pediat. Res. 8: 955-959 (1974)

Hemoglobin Barts neonate $\alpha$-thalassemia

\title{
$\alpha$-Thalassemia in Negro Infants
}

\author{
SHLOMO FRIEDMAN,(40) JEAN ATWATER, FRANCES M. GILL, AND ELIAS SCHWARTZ \\ Children's Hospital of Philadelphia and the Department of Pediatrics, University of Pennsylvania \\ School of Medicine, and the Cardeza Foundation for Hematologic Research, \\ Jefferson Medical College, Philadelphia, Pennsylvania, USA
}

\section{Extract}

A total of 104 of 693 Negro infants $(15.0 \%)$ had moderate or small amounts of hemoglobin Barts visible on starch gel electrophoresis. Moderate amounts were found in 21 infants $(3.0 \%)$ and small amounts in 83 infants $(12.0 \%)$. In 17 Negro infants judged to have moderate amounts of $\mathrm{Hb}$ Barts, the quantitation showed $2.0-9.3 \%$ with a mean of $5.4 \pm 2.1$ (1 SD). A significant decrease in mean cell volume and mean cell hemoglobin was found in the Negro neonate with more than $2 \% \mathrm{Hb}$ Barts studied at 4 days of age. In 10 Negro infants with more than $2.0 \% \mathrm{Hb}$ Barts studied at 4 days of age, the $\alpha /(\beta+$ $\gamma$ ) ratio was $0.97 \pm 0.06$ (1 SD) (range 0.88-1.06). In nine infants aged 5-24 months who had more than $2.0 \% \mathrm{Hb}$ Barts in the newborn period, including six infants studied in the first group, the mean $\alpha / \beta$ ratio was $0.74 \pm 0.06$, (range $0.65-0.83$ ). Each of the nine infants with more than $2.0 \% \mathrm{Hb}$ Barts at birth had marked microcytosis and hypochromia at 5-24 months despite adequate iron therapy. Two newborn infants with moderate levels of $\mathrm{Hb}$ Barts at birth $(8.2 \%$ and $6.8 \%)$ and balanced total globin synthesis had no free radioactive $\alpha$ chain by gel filtration studies. Our studies indicate clearly that the presence of more than $2 \% \mathrm{Hb}$ Barts in the newborn period denotes the presence of $\alpha$-thalassemia trait.
Speculation

In a group of Negro newborn infants, $3 \%$ had more than $2 \%$ $\mathrm{Hb}$ Barts. These infants had the genetic disorder, $\alpha$-thalassemia trait. An additional $12 \%$ of the infants had elevated levels of $\mathrm{Hb}$ Barts between $1 \%$ and $2 \%$. This group may also have an $\alpha$-thalassemia disorder, as has been shown in other racial groups. The absence of hydrops fetalis due to $\alpha$-thalassemia in Negro neonates suggests that the molecular defect of $\alpha$-thalassemia detected in Negro neonates differs from that seen in Orientals in that it is not associated with a complete absence of $\alpha$-chain synthesis.

$\alpha$-Thalassemia is a common genetic disorder of hemoglobin synthesis which occurs in many ethnic groups, including Chinese (18), Thai (23, 34), Italians (18), and American Negroes (27). Extensive population studies in Thailand have shown a correlation between the $\alpha$-thalassemia syndromes and the amount of $\mathrm{Hb}$ Barts present in the neonatal period $(22,23$, $33,34)$. $\mathrm{Hb}$ Barts is a tetramer of the $\gamma$-globin chain $\left(\gamma_{4}\right)$, a polypeptide which is found in association with $\alpha$ chain in fetal hemoglobin $\left(\mathrm{Hb} \mathrm{F}-\alpha_{2} \gamma_{2}\right)$.

The significance of $\mathrm{Hb}$ Barts in Negro neonates is controversial. Weatherall (35) has claimed that the presence of 